\title{
Assessment of Somaclonal Variation in Chrysan- themum (Dendranthema grandiflora Kitam.) using RAPD and Morphological Analysis
}

\author{
P. Kengkarj, P. Smitamana ${ }^{1}$ and Y. Fujime ${ }^{2}$ \\ Plant Biotechnology Research Centre, Faculty of Agriculture, Chiang Mai University, \\ Chiang Mai 50200, Thailand
}

Key words: Petal culture, Dendranthema grandiflora, Somaclonal variation, RAPD, Identification

\begin{abstract}
Novel chrysanthemum (Dendranthema grandiflora Kitam.) somaclones from seven commercial cultivars were obtained through the petal segments culture. Morphological variation of the derived clones observed from the field trials was found to be cultivar specific. The major variants within the same cultivar were found only color and inflorescence shape deviation, whereby leaf and stem characters remained unchanged. Distinct variations were found in the 'Pinkgin' cultivar that color changed from magenta to red. The morphological differences of the tested somaclones showed high correlation with the RAPD patterns analysis. The morphological differences of the tested somaclones were shown to be highly correlated using RAPD pattern analysis. RAPD markers, using ten primers could better separate each cultivar at $80 \%$ similarity value. All the somaclones could be singly separated at $90 \%$ similarity. However, the higher level of variability of RAPD patterns in chrysanthemum rendered these RAPD fragments as good candidates for somaclonal and cultivar identification. The results from this study revealed the potential increase in range of floral color and morphological changes of petal segment culture, thus this technique would be effectively used for novel plant production.
\end{abstract}

\section{Introduction}

Chrysanthemum (Dendranthema grandiflora) is one of the most important commercial cut flowers. Many of the chrysanthemum cultivars are believed to be periclinal chimeras involving flower color since whole series or families of cultivars have arisen through somatic mutation of seedling varieties or their sports. Several cultivars of chrysanthemum have shown vegetative and floral variation in explant-derived plants, including those from shoot tip calli (Bush et al. 1976), stems and capitulae (Miyazaki and Tashiro 1978), leaves (Sutter and

${ }^{1}$ Corresponding author. E-mail: <psporn@chiangmai.ac.th>. ${ }^{2}$ Department of Horticulture, Kyoto Prefectural University, Kyoto 606-8522, Japan. 
Langhans 1981) and florets (Stewart and Dermon 1970; Sutter and Langhans 1981; Khalid et al. 1989).

Malaure et al. (1991a) reported that shoots derived from ray florets of 16 cultivars of chrysanthemum showed more variation than plants regenerated from vegetative parts. Moreover, Ahloowalia (1992) developed 20 new variants, which differed in height, leaf, flower shape, petal size and curvature. Anyhow, leaf-callus derived plants, though showed some variable, and did not exhibit the same degree of deviation in flower color and shape as those regenerated from florets (Bush et al. 1976, Khalid et al. 1989).

Revelation of somaclonal variation in ornamental plants through tissue culture has produced plants with novel characteristics at frequencies in excess of natural variation under glass house or field conditions (Malaure et al. 1991b). However, in vitro selection and somaclonal variation are random processes and have yet to be used to achieve specific goals in chrysanthemum improvement (Rout and Das 1997).

Traditionally, cultivars identification has been based on morphological characteristics. The developments of new techniques, however, have allowed basing these analyses on DNA information. We have used RAPD for analysis of somaclonal variation among regenerated plants, as it is technically simple, quick to perform, requires very little plant material and yields true genetic markers, and above all, has been used widely which has proved to be an efficient tool for assessing of genetic stability in the tissue culture process (Brown et al. 1993, AlZahim et al. 1999, Ma et al. 2004, Adhikari et al. 2004, Qin et al. 2006).

The main objectives of the present study were to establish and optimize an efficient and stable system for high frequency direct shoot differentiation and regeneration plantlets from the petal segments of some chrysanthemum cultivars, while comparing the rate of obtaining variants and finding the relation between morphological changes and to assess the genetic variation at DNA level through the clonal phase by RAPD.

\section{Materials and Methods}

The ray florets were selected from seven chrysanthemum (Dendranthema grandiflora) cultivars, namely Biarizte, Yellow Biarizte, Storika, Pinkgin, Linker Pink, Dark Linker Salmon and Bari were analyzed in this study. After removing the ray florets from the inflorescence, they were washed with sterile distilled water for 3 - $5 \mathrm{~min}$. The surface was then sterilized with $\mathrm{HgCl}_{2}$ (1: 1000) supplemented with a few drops of Tween 20 for $10 \mathrm{~min}$ and rinsed three times with sterile distilled water. Each ray floret was cut into three parts (top, middle and basal portion, with size of ca. $0.4 \times 0.4 \mathrm{~cm}$ ) and the abaxial sides of the 
excised ray florets were placed on the surface of modified MS medium. Different combinations of NAA $(0.1,0.5,1.0 \mathrm{mg} / \mathrm{l})$ and BAP $(0.3,1.5,3.0 \mathrm{mg} / \mathrm{l})$ were tested for their effects on callus and shoot induction. Basal media were solidified with $7.0 \mathrm{~g} / \mathrm{l}$ agar and supplemented with $100.0 \mathrm{mg} / \mathrm{l}$ myo-inositol, $30.0 \mathrm{~g} / \mathrm{l}$ sucrose, $\mathrm{pH}$ 5.8 , were autoclaved $\left(121^{\circ} \mathrm{C}, 20 \mathrm{~min}\right)$. The experiments were conducted at $25^{\circ} \mathrm{C}$ under $16 \mathrm{hrs}$ photoperiod at $30 \mu \mathrm{mol} \mathrm{m} / 2 \mathrm{sec}$ supplemented by plant lamps (GroLux, Sylvania).

Data from the experiment were analyzed using ANOVA and LSD.

Agar on rooted shoots was washed thoroughly with tap water and transferred to the seedling tray containing the growing medium consisted of soil and compost at the ratio of $6: 1(\mathrm{v} / \mathrm{v})$. The plantlets were kept in a growth chamber for three weeks at $25^{\circ} \mathrm{C}$ in 16 hrs per day light and $85 \% \mathrm{RH}$. Cuttings from each regenerated clones were rooted in the trays in order to increase the plantlet vigour. After that, they were transplanted to Pong Yang, Chiang Mai, Thailand, with the spacing of $8 \times 8 \mathrm{~cm}$ in a $0.8 \mathrm{~m}$ wide and $25 \mathrm{~m}$ long bed. Ten shoots of the petal culture derived clones and ten shoots from each control cultivars were grown for the field performance trial. The artificial light from the incandescent lamps was applied $16 \mathrm{hrs}$ per day for the vegetative growth and 10 hrs per day for the reproductive growth. Ten shoots of each clone derived from petal culture derived plants and ten shoots of each control cultivar were randomly selected from the bed for the morphological study and statistical analysis.

Forty six decamer oligonucleotide primers (Operon Technologies, Inc.), kit A, B, and D were screened by PCR. The ten primers were selected after preliminary screening as shown in Table 1 . PCR reactions were performed by using Ready-To-Go PCR beads (Amersham Pharmacia Biotech.) for $25 \mu$ reaction volume. The thermo-cycle profile described by Huang et al. (2000) was programmed as follows: incubation at $94^{\circ} \mathrm{C}$ for $3 \mathrm{~min}$. DNA was amplified for 45 cycles in a Perkin Elmer (Gene Amp PCR Systems 9600) thermal cycle programmed at $94^{\circ} \mathrm{C}$ for $45 \mathrm{sec}, 40^{\circ} \mathrm{C}$ for $45 \mathrm{sec}$ and $72^{\circ} \mathrm{C}$ for $1 \mathrm{~min} 30 \mathrm{sec}$ and followed by one final extension cycle of $3 \mathrm{~min}$ at $72^{\circ} \mathrm{C}$. The amplification products were separated by electrophoresis in $1.7 \%(\mathrm{w} / \mathrm{v})$ agarose (Ultra-pure DNA Grade) gels with 1x TBE buffer, and stained with $10 \mathrm{mg} / \mathrm{ml}$ of ethidium bromide $(\mathrm{EtBr})$. The products were then visualized and photographed under exposure to UV light with UPP-1105 High Quality Printing paper Type1 (Normal). The molecular weights of the amplification products were calculated using an EZ load 100 bp PCR Molecular Ruler (Bio-Rad).

The polymorphisms in PCR amplification products were scored visually for presence (1) or absence (0) of bands. Band sharing was analyzed by Jaccard's coefficient of similarity. A dendrogram-based on the genetic distance matrix data 
was generated using Bio-Profile ${ }^{\circledR}$ Image (Bio1D++) analysis software to estimate relationships within the population.

\section{Results and Discussion}

Callus formation was found on the basal of each petal segment ca. 14 days after culture on the media. Number and appearance of calli derived from each petal were different among the tested cultivars. From three NAA and BAP concentrations tested, the combination of NAA and BAP at 0.5, 1.5 and 1.0, 3.0 $\mathrm{mg} / \mathrm{l}$, respectively rendered no significant difference on callus formation. However, the medium supplemented with $0.5 \mathrm{mg} / \mathrm{l} \mathrm{NAA}$ and $1.5 \mathrm{mg} / \mathrm{l} \mathrm{BAP}$ could induce more callus formation when compared to the others. This observation was supported by Ohishi and Sakurai (1988) who reported that petal culture of 21 cut-flower cultivars developed callus with more adventitious shoots on MS supplemented with $10 \mathrm{mg} / \mathrm{l}$ IAA, $10 \mathrm{mg} / \mathrm{l}$ BAP and $0.1 \mathrm{mg} / \mathrm{l} \mathrm{Kn}$. Furthermore, Kaul et al. (1990) showed that BAP and NAA were important for shoot growth in the leaf and stem culture. However, plants responded better to NAA than to BAP in optimum concentrations of $5 \mu \mathrm{M}$ for each hormone. The best combination of NAA and BAP concentrations was $5 \mu \mathrm{M}$ for each of them.

The numbers and characteristics of regenerated plants that showed variation from the control plants are shown in Table 2. The major variation (mainly in the 'Biarizte' and 'Yellow Biarizte') was found in ray floret shape which was tubular, flat or spoon type. Petal color and shape varied greatly in five cultivars which had red or purple petals. The two cultivars that had either white or cream petals showed no variation. Furthermore, the variations were also found in floret diameter, number of ray florets, fresh flower weight, number of inflorescence, plant height, and fresh leaf weight and leaf area. The difference of flowering date was marked in two cultivars; 'Storika' and 'Biarizte' from which high variation was detected in all characters.

Regeneration from petals of chrysanthemum has been achieved (Bush et al. 1976) and utilized for the production of new varieties via somaclonal variation. This observation was supported by Endo et al. (1990) who found that in regenerated plantlets from four kinds of explants, the number of ray florets increased through stem and leaf segment cultures although there was a tendency for a decrease of ray florets with young capitulla and ray floret cultures. With respect to the morphology of flower petals and color, no mutants were observed among explant sources. Tanaka et al. (2000) reported that somatic embryogenesis

was observed in ray floret explants of Chrysanthemum morifolium (Ramat.) Kitamura cv. Aboukyo on MS supplemented with high concentrations of IAA and $\mathrm{Kn}$. 
The tissue culture method as described by Malaure et al. (1991a) can be used to secure novel plant material exhibiting genetic traits resulting from natural mutation and variation. The observation was supported by Chang and Huang (2000) who found variations in plants regenerated from shoot tip or callus were cultivar dependent, Blue Mable showed the most variation, all plants regenerated from callus had more disk flowers and fewer ray florets. Debasis et al. (2000) also found yellow florets were removed from the white colored cultivar Kasturba Gandhi, cultured on MS medium supplemented with $0.2 \mathrm{mg} / \mathrm{l}$ NAA and $1 \mathrm{mg} / \mathrm{l} \mathrm{BAP}$.
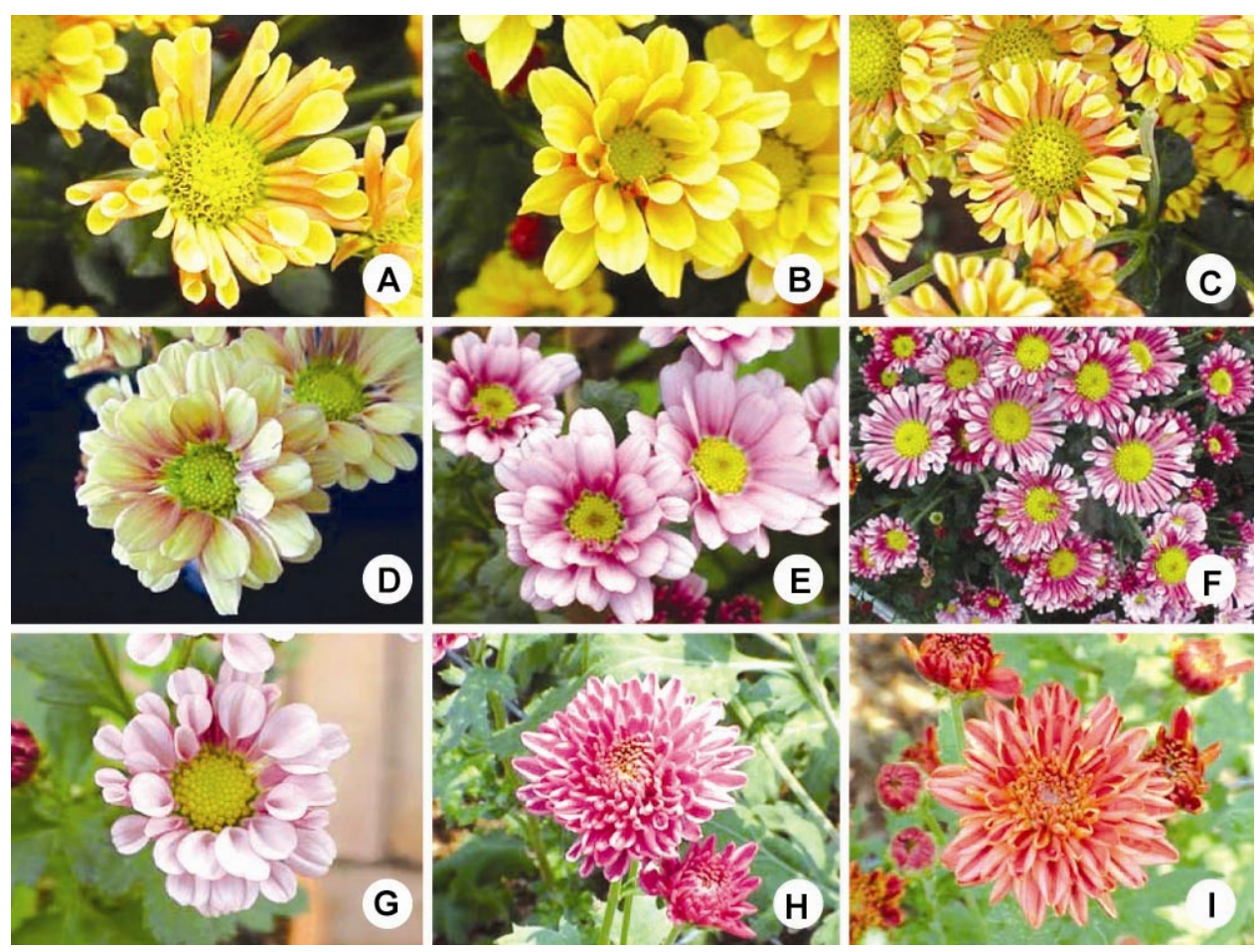

Fig. 1. Ray floret variation found in regenerated plants. (A-D) 'Yellow Biarizte' cultivar, (E-G) 'Biarizte' cultivar, $(\mathrm{H})$ control 'Pinkgin' cultivar and (I) variated red color of 'Pinkgin` cultivar.

Results showed that the rate of variations was cultivar dependent and occurred more frequently in the cultivars that the flower color was either red or purple, whereas cultivars that have white or cream flower color were not detected, as the pigment accumulation was different in each petal color. The characteristics of regenerated plants that exhibited some forms of floral or morphological variations, Fig. 1A-I were depended on cultivars. 
Cultivar identification and cultivar relatedness are important issues for horticultural breeders. The application of RAPD has proved to be a useful and rapid method to detect variations in different chrysanthemum varieties.

In this study, we have screened a total of 46 decamer oligonucleotide primers, and random-selected 29 somaclones from seven cultivars according to the characteristics, were employed in somatic variation detection by RAPD . Seven different chrysanthemum cultivars were studied using 10 primers after preliminary screening as shown in Table 1 . Higher genetic variability among the cultivars was found (Fig. 2). Almost all of the selected primers yielded extremely different banding patterns in each cultivar from which the DNA fragment patterns could be separated into seven distinct clusters. The similarity values ranged from 58 to $71 \%$. However, the clusters at 55\% similarity were separated into two groups which differed in shape and layer of ray florets (Table 2).

Table 1. Nucleotide sequences of the amplifiable primers used in the experiments (primer names were according to manufacturer's Operon Technologies).

\begin{tabular}{cc}
\hline Primer & Sequences $\left(5^{\prime}\right.$ to $\left.3^{\prime}\right)$ \\
\hline OPA-06 & GGTCCCTGAC \\
OPA-08 & GTGACGTAGG \\
OPA-09 & GGGTAACGCC \\
OPA-13 & CAGCACCCAC \\
OPA-18 & AGGTGACCGT \\
OPB-04 & GGACTGGAGT \\
OPB-08 & GTCCACACGG \\
OPB-18 & CCACAGCAGT \\
OPC-04 & CCGCATCTAC \\
OPC-06 & GAACGGACTC \\
\hline
\end{tabular}

This is in the line with the study by Wolff and Peter-Van Rijn (1993) which showed high level of polymorphism and clonal stability of RAPD fragments are useful for cultivar identification. Wolff (1996), however, obtained similar results, although in a previous work (Wolff et al. 1995) no differences between cultivars were detected. In addition to the number of the primers used, the correct selection of the primers may be an important factor in obtaining a rapid discrimination between samples. While, the study by Matin et al. (2002) which the rate of variation showed differences between varieties, but no significant difference was found between culture conditions.

Thus, results from this experiment indicate that the clusters in the RAPD dendrogram were based on flower characteristics, making this technique very useful in chrysanthemum cultivar identification. 
Ten primers (Table 1) were used to identify somaclones of the 'Storika' cultivar. The 'Linker Pink', 'Biarizte', 'Yellow Biarizte' and 'Pinkgin' cultivars were tested using four primers.

The 'Storika' cultivar could be separated into eight groups at $90 \%$ similarity by ten primers. Only ST/52 and ST/54 somaclones being closely related at 91\% similarity (Fig. 3). The highest number of 17 bands was obtained when OPA-13 primer was used, while most of lowest bands in each somaclone were obtained when OPA-06 primer was used (Table 3). The highest bands from these ten primers were 113 in ST/59 somaclone and the lowest were 51 bands in ST/56 somaclone, which separated into single at $48 \%$ similarity.

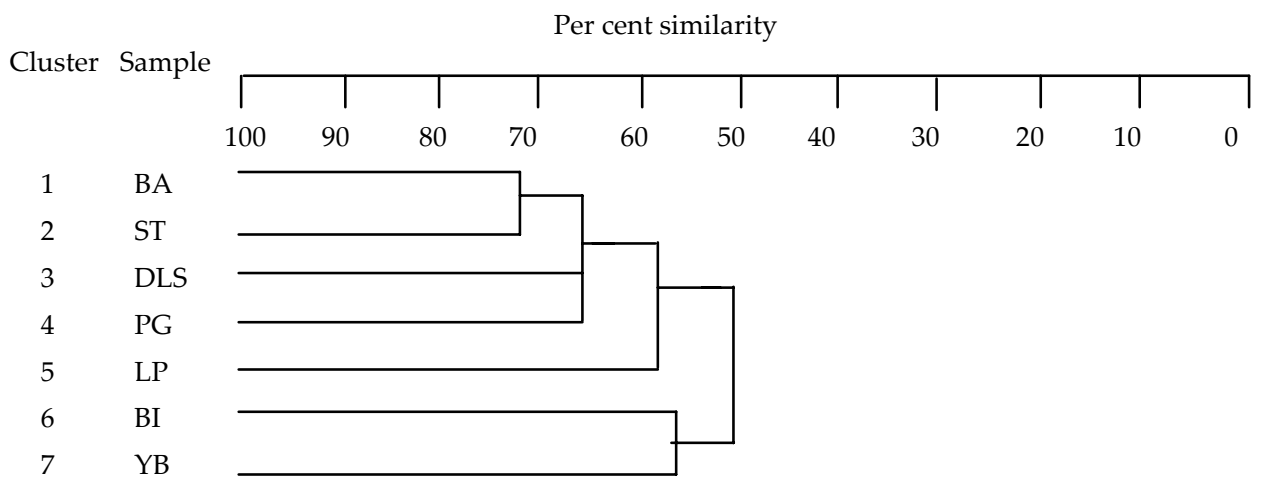

Fig. 2. Dendrogram representing the relationship of seven cultivars set based on RAPD markers, ten primers analyzed by Jaccard's coefficient. BA: Bari, ST: Storika, DLS: Dark Linker Salmon, PG: Pinkgin, LP: Linker Pink, BI: Biarizte, YB: Yellow Biarizte.
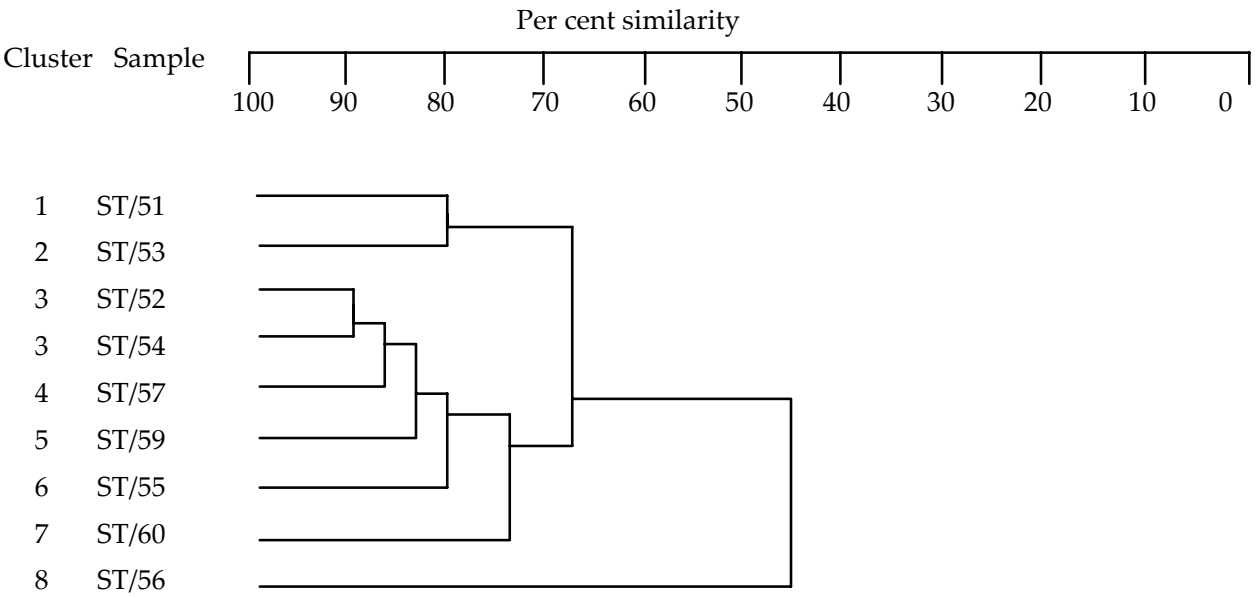

Fig. 3. Dendrogram representing the relationship of somaclones of 'Storika' cultivars set based on RAPD markers, ten primers analysed by Jaccard's coefficient. 


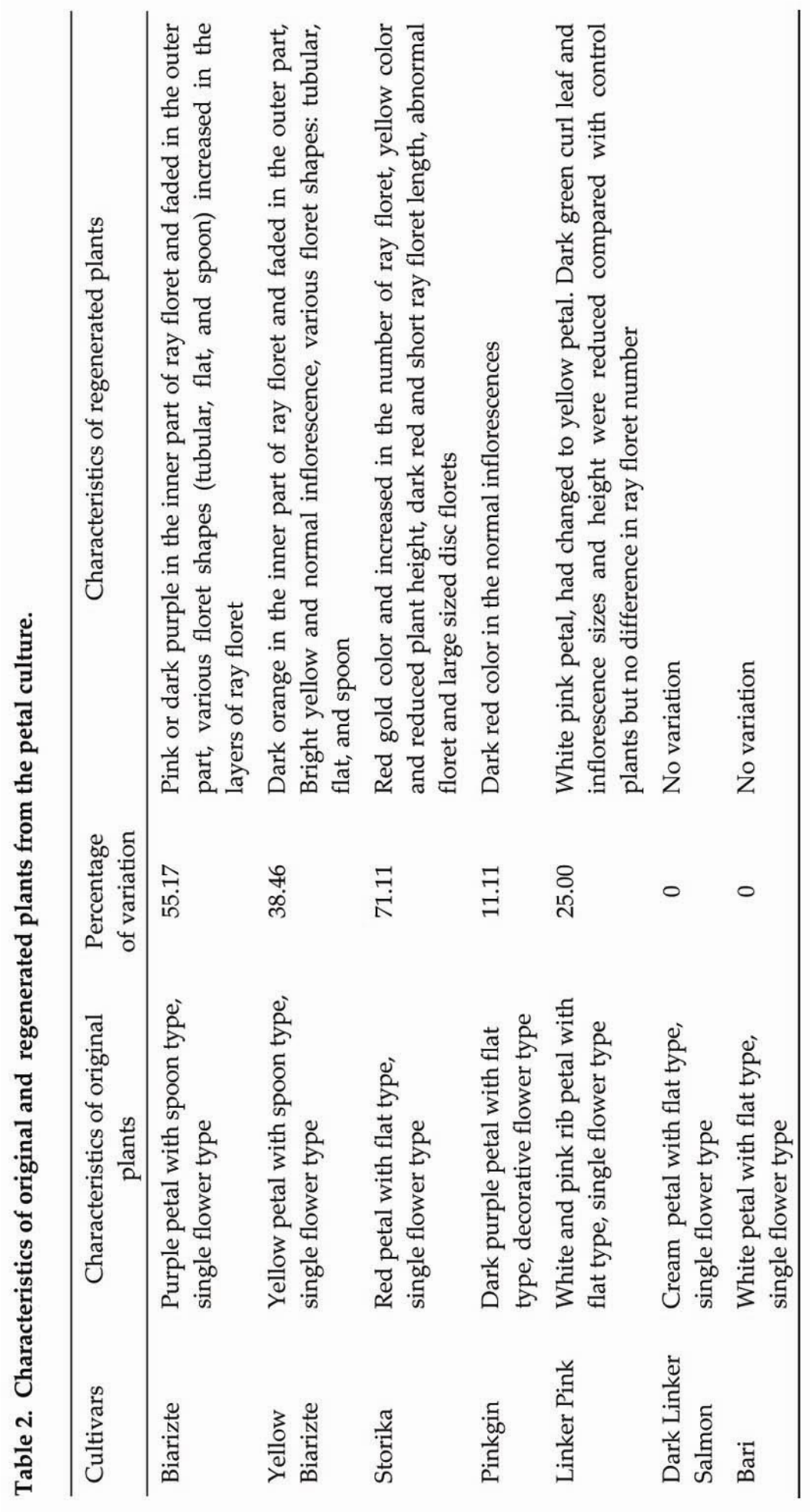


The results revealed of 10 primers show extremely different banding patterns in each 'Storika' somaclone. Almost the somaclones could be singly separated at $90 \%$ similarity. The similarity values ranged from 48 to $90 \%$. However, the clusters at $48 \%$ similarity were separated into two groups which differed in color and reduced plant height.

Table 3. Number of different fragments observed among 'Storika' somaclones using ten primers.

\begin{tabular}{cccccccccccc}
\hline \multirow{2}{*}{ Somaclone } & \multicolumn{10}{c}{ Primer } \\
\cline { 2 - 12 } & A06 & A08 & A09 & A13 & A18 & B04 & B08 & B18 & C04 & C06 & Total \\
\hline ST/51 & 2 & 12 & 8 & 10 & 12 & 10 & 10 & 11 & 10 & 8 & 93 \\
ST/52 & 4 & 13 & 10 & 16 & 9 & 7 & 8 & 12 & 7 & 10 & 96 \\
ST/53 & 4 & 12 & 9 & 6 & 14 & 11 & 9 & 11 & 11 & 9 & 96 \\
ST/54 & 5 & 13 & 12 & 17 & 9 & 9 & 8 & 11 & 9 & 12 & 105 \\
ST/55 & 5 & 13 & 8 & 16 & 8 & 9 & 8 & 9 & 9 & 8 & 93 \\
ST/56 & 2 & 5 & 5 & 13 & 7 & 2 & 5 & 5 & 2 & 5 & 51 \\
ST/57 & 4 & 13 & 10 & 15 & 9 & 7 & 8 & 12 & 7 & 10 & 95 \\
ST/59 & 5 & 14 & 11 & 14 & 10 & 14 & 8 & 12 & 14 & 11 & 113 \\
ST/60 & 5 & 13 & 11 & 16 & 9 & 6 & 7 & 13 & 6 & 11 & 97 \\
\hline
\end{tabular}

In this study, we distinguished the variations of somaclones that appeared variable in the previous field test. In addition, the somaclones of other cultivars were also distinguished from each other by RAPD patterns, while some somaclones were inseparable because the mutation did not manifest itself noticeably. As stated by Khalid et al. (1989), that in addition to not only chimeras, gene mutation and chromosome change are considered possible causes for somaclonal variations in chrysanthemum. The different results obtained for the somaclones studied in this work confirm this variation was established among different cultivars. The application of DNA fingerprinting for germplasm conservation and breeding allows the identification of species and cultivars and the determination of the evolutionary relationships between clones. It helps in the identification of duplications among accessions in the field and in tissue culture germplasm banks. It can also be used in the monitoring of genetic stability of the tissue culture material (i.e. somaclonal variation) and identification of trait markers for use in cross and mutation breeding programs (Onguso et al. 2004).

However, the high level of RAPD patterns variability in chrysanthemum renders these RAPD fragments as good candidates for somaclonal and cultivar identification and genetic analysis. 


\section{Acknowledgements}

Financial support from the Thailand Research Fund through the Royal Golden Jubilee Ph.D. Program (Grant No. PHD/ 00027/2541) to P. Kengkarj and P. Smitamana is acknowledged.

\section{References}

Adhikari TB, Yang X and Cavaletto JR (2004) Molecular mapping of Stbl, a potentially dutable gene for resistance to Septoria tritici blotch in wheat. Theor. Appl. Genet. 109: 944-953.

Ahloowalia BS (1992) In vitro radiation induced mutants in Chrysanthemum. Mutation Breeding News Lett. 39: 6.

Al-Zahim MA, Ford-Lloyd BV and Newbury HJ (1999) Detection of somaclonal variation in garlic (Allium sativum L.) using RAPD and cytological analysis. Plant Cell Reports 18: 473-477.

Brown TTH, Lange FD, Kranz E and Lorz H (1993) Analysis of single protoplast and regenerated plants by PCR and RAPD technology. Mol. Gen. Genet. 273: 311-317.

Bush SR, Earle ED and Langhans RW (1976) Plantlet from petal segments, petal epidermis, and shoot tips of the periclinal chimera, Chrysanthemum morifolium "Indianapolis". Amer. J. Bot. 63: 729-737.

Chang S and Huang M (2000) The variation in tissue culture-derived plants of chrysanthemum. J. Chinese Soc. Hort. Sci. 46(1): 21-34.

Debasis CA, Mandal AK and Datta SK (2000) Retrieval of new coloured chrysanthemum through organogenesis from sectorial chimera. Curr. Sci. 78(9): 10601061.

Endo M, Sakaki T and Inada I (1990) Creation of mutants through tissue culture of edible chrysanthemums, Chrysanthemum morifolium Ram. I. Especially the relationship among the different explants and variation in their regenerated plants. J. of the Fac. Agri., Iwate Univ. 20: 17-33.

Huang SC, Tsai CC and Sheu CS (2000) Genetic analysis of Chrysanthemum hybrids based on RAPD molecular markers. Bot. Bull. Acad. Sin. 41: 257-262.

Kaul V, Miller RM, Hutchinson JF and Richards D (1990) Shoot regeneration from stem and leaf explants of Dendranthema grandiflora Tzvelev (Chrysanthemum moriflorium Romat.). Plant Cell Tissue and Organ Culture 21: 21-30.

Khalid N, Davey MR and Power JB (1989) An assessment of somaclonal variation in Chrysanthemum morifolium: The generation of plants of potential commercial value. Scientia Horticulturae 38: 287-294.

Ma R, Yli-Mattila T and Pulli S (2004) Phylogenetic relationships among genotypes of worldwide collection of spring and winter rye (Secale cereale L.) determined by RAPD-PCR markers. Hereditas 140: 210-221.

Malaure RS, Barclay G, Power JB and Davey MR (1991a) The production of novel plants from florets of Chrysanthemum morifolium using tissue culture 1 . Shoot regeneration from ray florets and somaclonal variation exhibited by the regenerated plants. J. Plant Physiol. 139: 8-13. 
Malaure RS, Barclay G, Power JB and Davey MR (1991b) The production of novel plants from florets of Chrysanthemum morifolium using tissue culture. 2. Securing natural mutations (Sports). J. Plant Physiol. 139: 14-18.

Matin C, Uberhuaga E and Perez C (2002) Application of RAPD markers in the characterization of Chrysanthemum varieties and the assessment of somaclonal variation. Euphytica 127: 247-253.

Miyazaki S and Tashiro Y (1978) Tissue culture of Chrysanthemum morifolium. IV. Explant sources for stem segment culture. Agr. Bull. Saga Univ. 44: 67-78.

Ohishi K and Sakurai Y (1988) Morphological changes in Chrysanthemum derived from petal tissue. Res. Bull. Aichiken Agric. Res. Cent. 20: 278-284.

Onguso JM, Kahangi EM, Ndiritu DW and Mizutani F (2004) Genetic characterization of cultivated bananas and plantains in Kenya by RAPD markers. Scientia Horticulturae 99(1): 9-20.

Qin Y, Gao LH, Pulli S and Guo YD (2006) Shoot differentiation, regeneration of cauliflower and analysis of somaclonal variation by RAPD. Hereditas 143: 91-98.

Rout GR and Das P (1997) Recent trends in the biotechnology of Chrysanthemum: A critical review. Scientia Horticulturae 69: 239-257.

Stewart RN and Dermen H (1970) Somatic genetic analysis of the apical layers of chimeral sports in chrysanthemum by experimental production of adventitious sshoots. Amer. J. Bot. 57: 1061-1071.

Sutter E and Langhans RW (1981) Abnormalities in Chrysanthemum regenerate from long-term culture. Annual Botanical 48: 559-568.

Tanaka K, Kanno Y, Kudo S and Suzuki M (2000) Somatic embryogenesis and plant regeneration in chrysanthemum [Dendranthema grandiflorum (Ramat.) Kitamura]. Plant Cell Rep. 19: 946-953.

Wolff K (1996) RAPD analysis of sporting and chimerism in chrysanthemum. Euphytica 89: $159-164$

Wolff K and Peters-Van Rijn J (1993) Rapid detection of genetic variability in chrysanthemum (Dendranthema grandiflora Tzvelev.) using random primers. Heridity 71: 335-341.

Wolff K, Zietiewicz E and Hofstra H (1995) Identification of chrysanthemum cultivars and stability of DNA fingerprint patterns. Theor. Appl. Genet. 91: 439-447. 